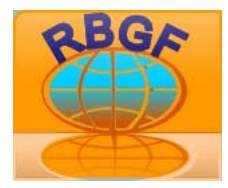

\title{
EVOLUÇÃO PALEOAMBIENTAL DOS DEPÓSITOS DE TANQUES EM FAZENDA NOVA, PERNAMBUCO - NORDESTE DO BRASIL
}

\author{
Danielle Gomes da Silva ${ }^{1} \mathrm{e}$ \\ Antonio Carlos de Barros Corrêa ${ }^{2}$ \\ Artigo recebido em 21/08/2009 e aceito para publicação em 31/08/2009.
}

\section{RESUMO}

A análise geomorfológica dos ambientes atuais constitui uma importante ferramenta para a compreensão da seqüência evolutiva da paisagem no passado geológico recente, e um aspecto essencial para tal entendimento está na associação do registro estratigráfico aos estudos geomorfológicos como instrumento material para a interpretação da evolução da paisagem. Sendo assim, o objetivo da pesquisa foi interpretar através da análise geomorfológica, morfoestratigráfica e sedimentológica das feições deposicionais em Brejo da Madre de Deus, Pernambuco, associadas a preenchimento de tanques, como os sistemas geomorfológicos têm respondido aos fluxos oscilantes de energia ao longo do Quaternário superior. As áreas tipos escolhidas para a pesquisa foram o tanque da Fazenda Logradouro no distrito de Fazenda Nova, situado no município de Brejo da Madre de Deus. Após a identificação, em campo, das relações estratigráficas na área de amostragem, foram coletadas amostras para a análise sedimentológica, micromorfológica e para datação por Luminescência Opticamente Estimulada (LOE). Os sedimentos analisados variam de pobremente a moderadamente selecionados, com forte tendência à assimetria muito positiva. A curtose reflete a ocorrência de amostras com predomínio de distribuições muito platicúrticas e a ocorrência de um pico de concentração de cascalho, sugerindo controle direto dos mantos de alteração gerados sob condições semi-áridas, que forneceram o material para a colmatação dos tanques e formação de rampas de colúvio, mediante um regime de transporte de alta energia. Os resultados de datação por LOE obtida para as amostras analisadas indicam a ocorrência de períodos pontuais durante os quais ocorreu a remobilização dos mantos de intemperismo para o eixo deposicional do tanque, mediante a operação de eventos de grande magnitude e baixa recorrência, sob diversas combinações de semiaridez desde o penúltimo máximo glacial (PMG).

Palavras-chave: Depósito de Tanques, Morfoestratigrafia, Datação por LOE.

\footnotetext{
${ }^{1}$ Doutoranda do Programa de Pós-Graduação em Geografia da Universidade Federal de Pernambuco (UFPE) Centro de Filosofia e Ciências Humanas, Avenida Professor Moraes Rego, 1235, Cidade Universitária, Recife, Pernambuco. CEP 50670-901. (dannyavlis@yahoo.com.br).

${ }^{2}$ Prof. Dr. Adjunto do Departamento de Ciências Geográficas da Universidade Federal de Pernambuco (UFPE) Centro de Filosofia e Ciências Humanas, Avenida Professor Moraes Rego, 1235, Cidade Universitária, Recife, Pernambuco. CEP 50670-901 (dbiase2001@terra.com.br)
}

Silva, D. G.; Corrêa, A. C. B. 
RBGF- Revista Brasileira de Geografia Física

Recife-PE, Vol.2 n.02, maio-agosto 2009, 43-56

\title{
PALAEOENVIRONMENTAL DEVELOPMENTS IN WEATHERING PIT INFILL IN FAZENDA NOVA, PERNAMBUCO - NORTHEAST BRAZIL
}

\begin{abstract}
Quaternary sediments and their resulting agradational landforms represent the record of geomorphic processes which played a significant role in the evolution of the landscape, mainly in the tropical platformal contexts. Being self-contained depressions, weathering pits work as true geochronometers for the assessment of palaeoenvironmental evolution within the semi-arid Northeast of Brazil. This work aimed at defining the geomorphologic meaning of weathering pits deposits and establishing a possible connection between the origin of these geomorphic units and their infill. Such procedure may enhance the understanding of the Quaternary evolution of the area, especially because the pits are still closely connected with current surface dynamics in the area. The study area is located in the district of Fazenda Nova which lies $190 \mathrm{~km}$ to the west of Recife, the capital city of Pernambuco State. The analysis of depositional events in the weathering pit of Lagradouro farm was conducted from a morphostratigraphic approach. Following the field identification of stratigraphic relations within the pit, samples were collected for sedimentological and micromorphological analysis, X-ray diffraction of clay minerals, and OSL dating. The lab procedures aimed at providing a qualitative framework for the reconstruction of depositional events in the area. The results obtained indicated the occurrence of punctuated depositional events in which the weathering mantle was washed into the axis of the weathering pit. These must have been high magnitude, low recurrence events responding to climatic triggers under varied degrees of aridity since the LGM.
\end{abstract}

Keywords: Weathering pit infill, morphostratigraphy, OSL dating.

\section{INTRODUÇÃO}

O estudo do relevo, sobretudo dos modelados deposicionais, vem permitindo identificar eventos desestabilizadores da estrutura superficial da paisagem, de grande magnitude, capazes de reorganizar o comportamento dos processos geomórficos. Desta forma, a paisagem geomorfológica e sua evolução dependem da atuação em conjunto de diversos fatores, representados em diferentes escalas de espaço e tempo, que influenciam os processos superficiais tendendo a gerar uma multiplicidade de Silva, D. G.; Corrêa, A. C. B. resultados complexos e interconectados na morfologia da paisagem.

A identificação e análise dos processos nas encostas foram consideradas como de importância fundamental para a determinação dos agentes modeladores das formas de relevo agradacionais no Município de Brejo da Madre de Deus. Assim, a premissa norteadora deste estudo foi a de que estas evidêr 47 geomorfológicas - os depósitos de tanques e rampas coluviais - embora confinados espacialmente estejam associadas às flutuações climáticas do Quaternário superior, cujas 


\section{RBGF- Revista Brasileira de Geografia Física \\ Recife-PE, Vol.2 n.02, maio-agosto 2009, 43-56}

pulsações de maior energia alcançaram até mesmo o Holoceno médio e superior, com repercussões notáveis sobre o registro sedimentar e arranjos páleo-ambientais da região.

Diante dessa assertiva, a análise da evolução do relevo através dos depósitos correlativos e a morfoestratigrafia, caracterizam-se como importantes recursos metodológicos para se identificar a dinâmica geomorfológica atual e pretérita. A importância desta abordagem reside na sua ênfase morfogenética, uma vez que cada unidade morfoestratigráfica está alicerçada sobre materiais que resgatam a história erosiva/deposicional da área.

\section{A ABORDAGEM MORFOESTRATIGRÁFICA COMO INSTRUMENTO PARA A RECONSTRUÇÃO AMBIENTAL}

A análise geomorfológica dos ambientes atuais constitui a base para a compreensão da seqüência evolutiva da paisagem no passado geológico recente. Sendo assim, um aspecto essencial para tal entendimento está na associação do registro estratigráfico aos estudos geomorfológicos como instrumento material para a interpretação da evolução da paisagem.
A análise estratigráfica de depósitos quaternários, por sua vez, deve considerar os diferentes padrões de organização morfológica, já que estes ocorrem distribuídos irregularmente sobre as múltiplas formas de relevo. Desta forma, a abordagem morfoestratigráfica visa correlacionar o estudo das formas à temporalidade e características intrínsecas dos materiais estruturadores da paisagem.

Sobre morfoestratigrafia, Suguio (1999) afirma que esta é de vital importância para a reconstituição da história da evolução geomorfológica de uma área, onde possam ser identificadas as superfícies e seus materiais, estabelecendo dessa forma a relação de antiguidade entre as unidades e sua correlação com áreas mais amplas.

Este conceito teve sua origem com Frye \& Willman (1962) quando definiram as unidades morfoestratigráficas como compreendendo corpos litológicos identificados, basicamente, através das formas de relevo a eles associadas, podendo ou nã 48 distintos litologicamente das uniaaaes contíguas, subordinando assim, a estratigrafia às formas de relevo.

Em estudos mais recentes, Meis e Moura (1984) através da análise comparada entre a geometria das formas superficiais e dos corpos que constituem a sua estrutura superficial, 


\section{RBGF- Revista Brasileira de Geografia Física \\ Recife-PE, Vol.2 n.02, maio-agosto 2009, 43-56}

sugeriram a restrição do conceito às condições nas quais seja possível detectar, com base na lito ou na aloestratigrafia, uma relação genética direta entre o depósito e a forma topográfica tornando possível o estabelecimento de relações morfoestratigráficas menos abrangentes e mais coerentes com o significado estratigráfico dos depósitos.

Dentro de um contexto geomorfológico, as feições de rampas de colúvio e terraços fluviais de acumulação surgem como importante significado morfoestratigráfico (Moura, 2003), sendo formas topográficas associadas à deposição vinculadas a uma dinâmica complexa que possibilita a reconstituição dos processos que contribuíram para a evolução da paisagem.

Camargo Filho \& Bigarella (1998) empregando parâmetros sedimentológicos tradicionais na distinção dos processos envolvidos na deposição de colúvios no vale do rio Bananas - Paraná verificaram que os processos responsáveis pela evolução geomorfológica em área de encostas e dos vales fluviais assemelhavam-se àqueles já documentados por Moura e Meis (1986), fornecendo, assim, um quadro da evolução quaternária das regiões estudadas com base na definição de unidades morfoestratigráficas.

Moura \& Mello (1991) adotando critérios aloestratigráficos de classificação associado a mapeamento geomorfológico de detalhe para a Região de Bananal (SP/RJ), destacaram a presença de descontinuidades estratigráficas de significado regional, associadas a discordâncias erosivas e paleossolos. Segundo os autores, a compartimentação do registro sedimentar documenta uma sucessão de eventos de instabilidade e estabilidade dentro da evolução neoquaternária da paisagem, representada por diferentes registros sedimentares coluviais e aluviais superpostos e litologicamente bastante similares.

O Pleistoceno na região estaria representado por depósitos coluviais subdivididos em duas unidades aloestratigráficas: Aloformação Santa Vitór 49 Aloformação Rio do Bananal, reunindo colúvios argilo-arenosos, intercalados com níveis de cascalhos, cujo topo seria delimitado por um perfil de solo intermediário entre podizólico e latossolo, onde o paleo-horizonte A foi datado em cerca de 9.800 anos A.P.

A sedimentação holocênica, ainda segundo Moura e Mello (op. cit.), teria se iniciado com depósitos argilosos, orgânicos, de origem flúvio-lacustre, reunidos sob a denominação de Aloformação Rio das Três Barras, datados em aproximadamente 9.500 


\section{RBGF- Revista Brasileira de Geografia Física \\ Recife-PE, Vol.2 n.02, maio-agosto 2009, 43-56}

anos A.P., sendo esta o primeiro registro da evolução sedimentar durante o Holoceno.

Modenesi \& Toledo (1996) aplicando a mesma abordagem para o Planalto de Itatiaia constataram que setores inferiores das vertentes do vale do Ribeirão das Flores e alvéolos menores, depósitos de tálus suspensos e duas gerações de colúvios testemunhariam fases de intensificação da erosão nas vertentes. $\mathrm{O}$ resgate paleoecológico inferido pelas autoras referese a eventos de climas úmidos e talvez mais quentes que favoreceram a alteração do regolito, passando a uma fase de intensificação ou concentração das chuvas, capaz de explicar o desencadeamento de corridas de lama que depositaram a primeira geração de colúvios (CI). Nos últimos 8.000 anos, condições úmidas, mas com menores oscilações de temperatura e fases de intensificação dos processos de gelifração, teriam sido responsáveis pela deposição dos materiais finos e cascalhosos da segunda formação de colúvios (CII).

Corrêa et al. (2004) aplicando a abordagem morfoestratigráfica visando desenvolver comparações entre os modelos qualitativos de evolução geomorfológica dos modelados deposicionais situados sobre as superfícies elevadas do Planalto da Borborema, Nordeste do Brasil, e seus congêneres em setores do Planalto Atlântico (Serra da Mantiqueira) no Sudeste do país, constataram a ocorrência de um retardo do sistema climático em responder ao aumento da umidade pós-glacial no Nordeste do Brasil, com a sedimentação basal dos colúvios ocorrendo entre 8,5 e $10 \mathrm{Ka} \mathrm{AP}$, enquanto no Sudeste esta sedimentação corresponde ao intervalo de 10 a 12 Ka. No Nordeste a sedimentação atinge um máximo no Holoceno superior a médio, por volta dos 6 a 7Ka AP, o que coincide com o máximo pluvial na região, havendo um termo brusco no Holoceno médio por volta dos 5 ka AP, com a estabilização da circulação atmosférica contemporânea (Célula de Walker). Enquanto isso no Sudeste a retomada da umidade dentro do Holoceno superior - $\quad$ condições úmidas penecontemporâneas - desencadeia episódios de sedimentação nas encostas que se confundirão com aqueles advindos da intensa antropização da paisagem já no período histórico atual - mudanças de uso da terra e oscilações climáticas decenais.

Considerando-se que as seqüências deposicionais constituem o único registro material preservado que explica a história evolutiva da paisagem, a associação entre forma e depósito tem-se mostrado como um instrumento imprescindível à interpretação da dinâmica ambiental, representando o elo que 


\section{RBGF- Revista Brasileira de Geografia Física \\ Recife-PE, Vol.2 n.02, maio-agosto 2009, 43-56}

une os processos ocorridos no passado e que ocorrem no presente dentro do contexto evolutivo da paisagem geomorfológica.

\section{DATAÇÃO PELO MÉTODO DA LUMINESCÊNCIA OPTICAMENTE ESTIMULADA (LOE)}

As vantagens do método da LOE sobre os demais procedimentos de datação de sedimentos recentes, como o $\mathrm{C}^{14}$, por exemplo, advém do fato de este explorar uma propriedade física - a luminescência inerente aos sólidos cristalinos (minerais) encontrados no próprio depósito, prioritariamente o quartzo e o feldspato. Assim sendo, a LOE se converte em método de datação absoluta de eventos deposicionais. Sua abrangência temporal vai desde cerca de 100 anos ap. até 1Ma, dependendo dos níveis de saturação do material analisado (AITKEN, 1998; WAGNER, 1998), portanto o método da LOE se presta para a datação de eventos deposicionais ocorridos ao longo do Quaternário, desde eventos climáticos regionais de grande magnitude (mudanças nos padrões de circulação regional), eventos tectônicos que afetaram a rede de drenagem (inversão e capturas por soerguimento das cabeceiras), até episódios erosivos recentes, desencadeados por alterações nos padrões de uso do solo.

Os métodos de datação por luminescência abrangem uma gama de técnicas baseadas no acúmulo de cargas radioativas produzidas por uma população de elétrons aprisionados em minerais cristalinos. Estes métodos são capazes de estabelecer o período de tempo transcorrido desde que a população aprisionada de elét 51 foi liberada pela última vez.

O evento de liberação da carga acumulada para os materiais sedimentares é o instante em que este material foi exposto à luz diurna pela última vez, antes de ser recoberto por novo episódio deposicional. A técnica se impôs a partir da década de 1980 e das contribuições de Huntley et al. (1985; 1988). A descoberta mais significativa foi, sem dúvida, a da possibilidade de medir o sinal de luminescência diretamente relacionado à carga da população de elétrons aprisionada no cristal, mediante estímulo luminoso, assim definindo o próprio método da LOE (Luminescência Opticamente Estimulada).

Segundo Stokes (1999) a abordagem teórica da LOE é mais coerente do que a da TL (Termoluminescência), muito utilizada até o surgimento do novo método, principalmente ao ser aplicado a depósitos sedimentares de ambientes aquosos, pois o mecanismo de liberação das cargas aprisionadas por foto-

Silva, D. G.; Corrêa, A. C. B. 


\section{RBGF- Revista Brasileira de Geografia Física \\ Recife-PE, Vol.2 n.02, maio-agosto 2009, 43-56}

estímulo é mais próximo do natural, decorrente da iluminação solar, do que o térmico utilizado pela TL.

O método da LOE presume que qualquer carga pretérita de elétrons contida em um sedimento é substancialmente reduzida, ou completamente removida, durante os processos de erosão, transporte e sedimentação, restando apenas uma pequena carga residual não removível. Geofrey-Smith et al. (1988) demonstraram que no caso do quartzo e do feldspato, a redução do sinal por estímulo óptico chega a níveis muito baixos, obtendo-se valores residuais inferiores a 5\% da carga inicial após uma exposição à luz do sol por um minuto.

\section{A ÁREA DE ESTUDO}

A área de estudo localiza-se na porção centro-leste do estado de Pernambuco, nos distritos de Fazenda Nova, município de Brejo da Madre de Deus, a $200 \mathrm{~km}$ da cidade do Recife, inserido dentro da folha topográfica Belo Jardim (SC-24-X-B-III), delimitado entre as coordenadas $8^{\circ} 04^{\prime} 10^{\prime \prime} \mathrm{e}$ $8^{\circ} 22^{\prime} 26^{\prime \prime}$ de latitude sul e $36^{\circ} 17^{\prime} 16^{\prime \prime}$ e $36^{\circ} 30^{\prime}$ de longitude oeste (Figura 01). Inserido dentro dos domínios da bacia hidrográfica do Rio Capibaribe, o corpo granítico da área é integrante do Batólito Caruaru-Arcoverde, o maior corpo da associação cálcio-alcalina de alto potássio da Província Borborema.

Na área de Fazenda Nova a sedimentação quaternária encontra-se, em sua maioria, associada à ocorrência de tanques em virtude destes constituírem setores de armazenamento de sedimentos na paisagem semi-árida aqui considerada. O trabalho de campo concentrouse no tanque da Fazenda Logradouro que apresenta formato ocelar, com diâmetro superior à profundidade (27m de cumprimento X 8,90m de largura) evidenciando a ocorrência de zonas de intercessão de linhas de fraturas verticais com planos das juntas de alívio de pressão subparalelos à superfície do terreno, que facilitam a penetração horizontal da água, favorecendo o crescimento lateral da marmita em detrimento de sua profundidade. Este “tanque” está associado a um granito pórfiro, e geomorfologicamente restrito à ocorrência de relevos residuais sob a forma de "inselbergs", porém com morfologia atual evoluindo para relevo em tors, produzido através da ação da erosão diferencial e remoção dos mantos de intemperismo (Figura 02). 


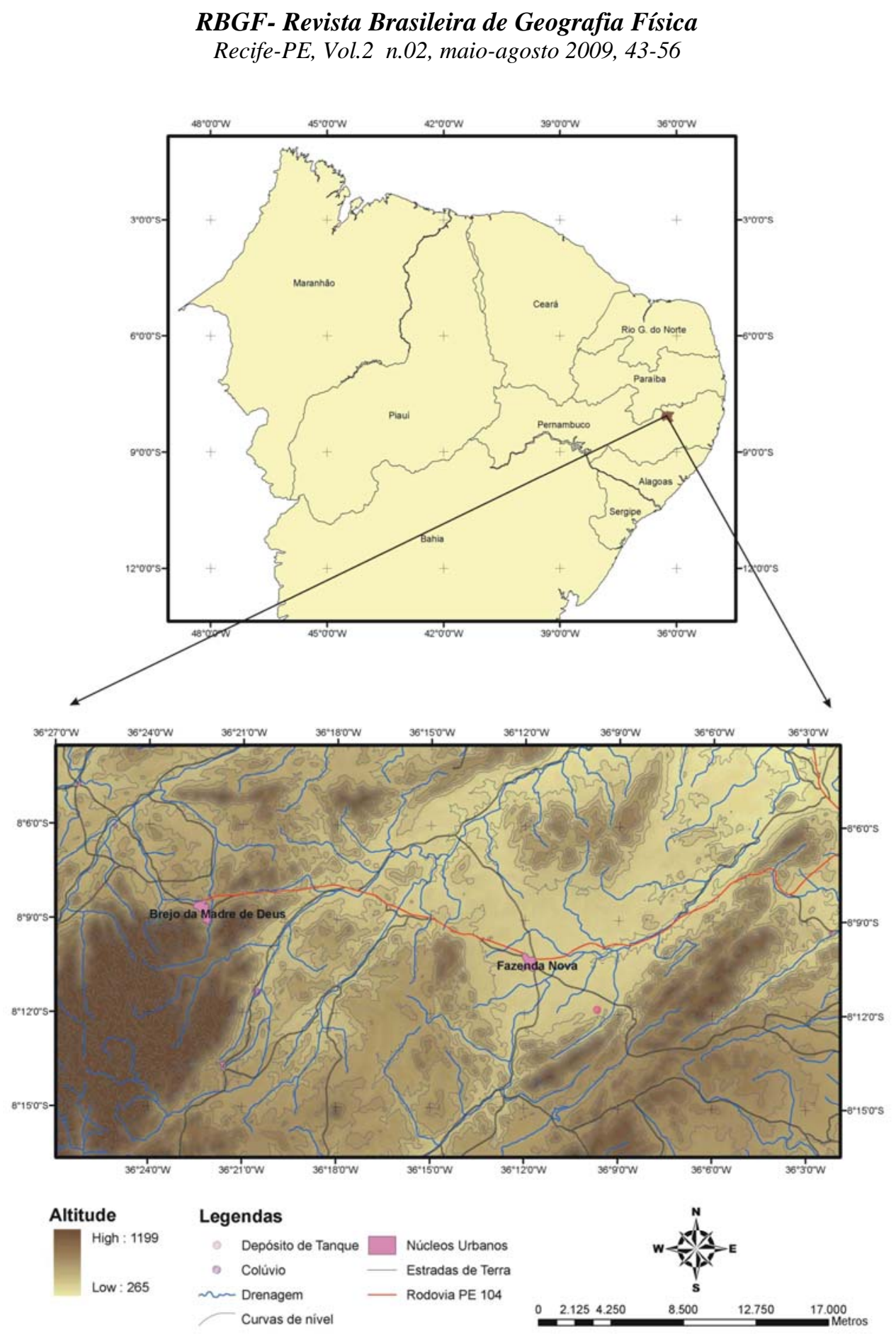

Figura 1: Localização da área de estudo

Silva, D. G.; Corrêa, A. C. B. 


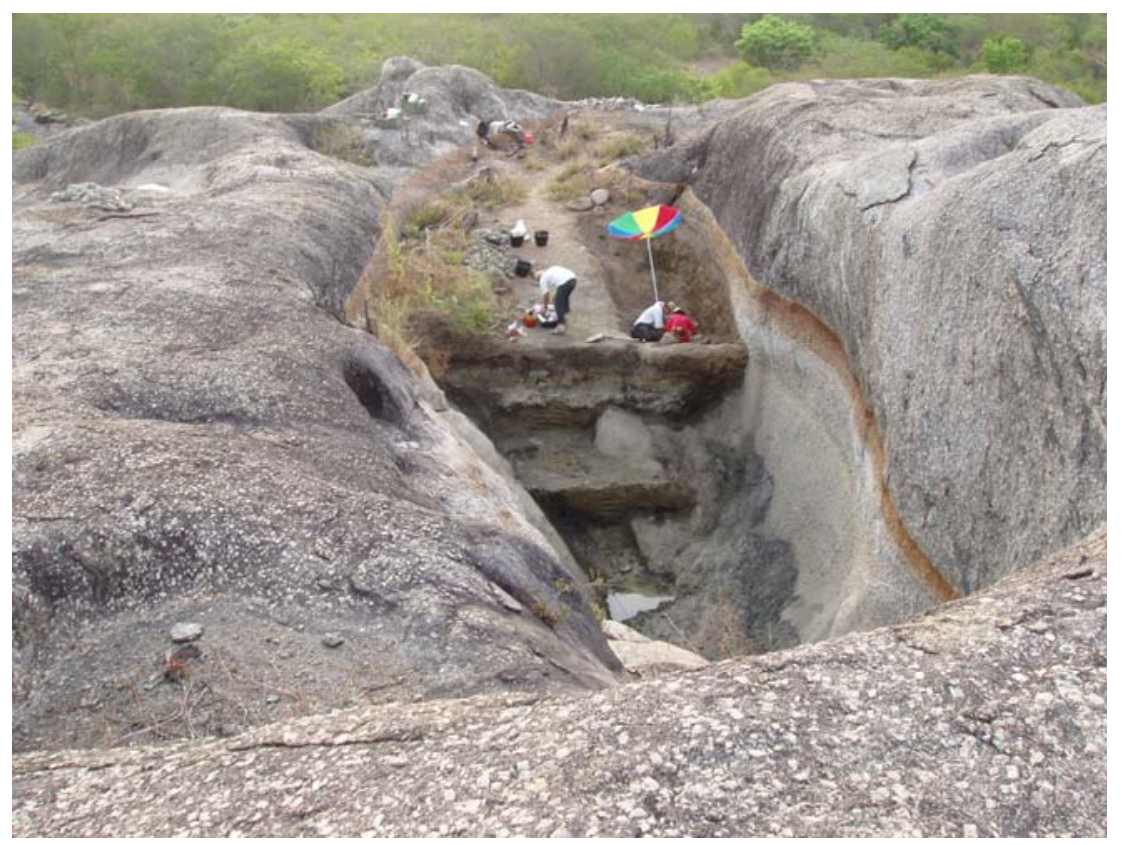

Figura 2: Visualização da área de coleta

\section{A MORFOESTRATIGRÁFICA PARA O DEPÓSITO DE TANQUE A PARTIR DAS SEÇÕES ESTRATIGRÁFICAS}

O depósito que preenche o tanque em Fazenda Nova apresenta espessura de 3,20 metros da base ao topo, exibindo quatro unidades estratigráficas distintas (Figura 03). A unidade basal de cascalho (amostra Incó 30/1A e 70/1A) possui matriz argilo-arenosa, com grãos de quartzo e feldspatos pobremente selecionados, predomínio de grãos angulosos e grande concentração de pirita. A fração grossa apresenta bioclastos de ossos e dentes de mamíferos pleistocênicos esparsos e fragmentados. Os clastos são seixos de feldspatos angulosos e fragmentos de rochas. Abaixo dessa unidade basal, encontra-se o embasamento cristalino alterado.

A segunda unidade é um conglomerado suportado por clastos e bioclastos (ossos da megafauna) com cimentação carbonática formando um nível endurecido (amostra Incó 140/1A). Os bioclastos são constituídos por ossos cranianos e pós-cranianos em sua grande maioria, dentes e placas dérmicas isoladas e elevado número de fragmentos de ossos não identificáveis taxonomicamente.

A terceira unidade é um cascalho suportado por matriz areno-argilosa de estrutura maciça (amostra Incó 160/1A). A

Silva, D. G.; Corrêa, A. C. B. 


\section{RBGF- Revista Brasileira de Geografia Física}

Recife-PE, Vol.2 n.02, maio-agosto 2009, 43-56

camada apresenta grãos pobremente

O quarto nível amostrado é um cascalho selecionados e angulosos, ricos em quartzo, suportado por matriz areno-argiloso, feldspato, fragmentos de rochas e filamentos pobremente selecionado, com freqüentes de carbonato de cálcio, representando um paleossolo inumado com o antigo horizonte B cálcico truncado pela deposição da fragmentos de rocha e fenoclastos do tamanho seixo, angulosos, ricos em quartzo e feldspato unidade subseqüente. O nível de ferruginização nodular que corta esta unidade pode representa uma posição subaérea do pacote antes da deposição das camadas subjacentes. com plano de clivagem preservado (amostra Incó 190/1A). Esta camada apresentou ausência de carbonato de cálcio e a presença de acumulação de seixos rolados no topo do perfil sugere a existência de um paleopavimento formado por erosão laminar.

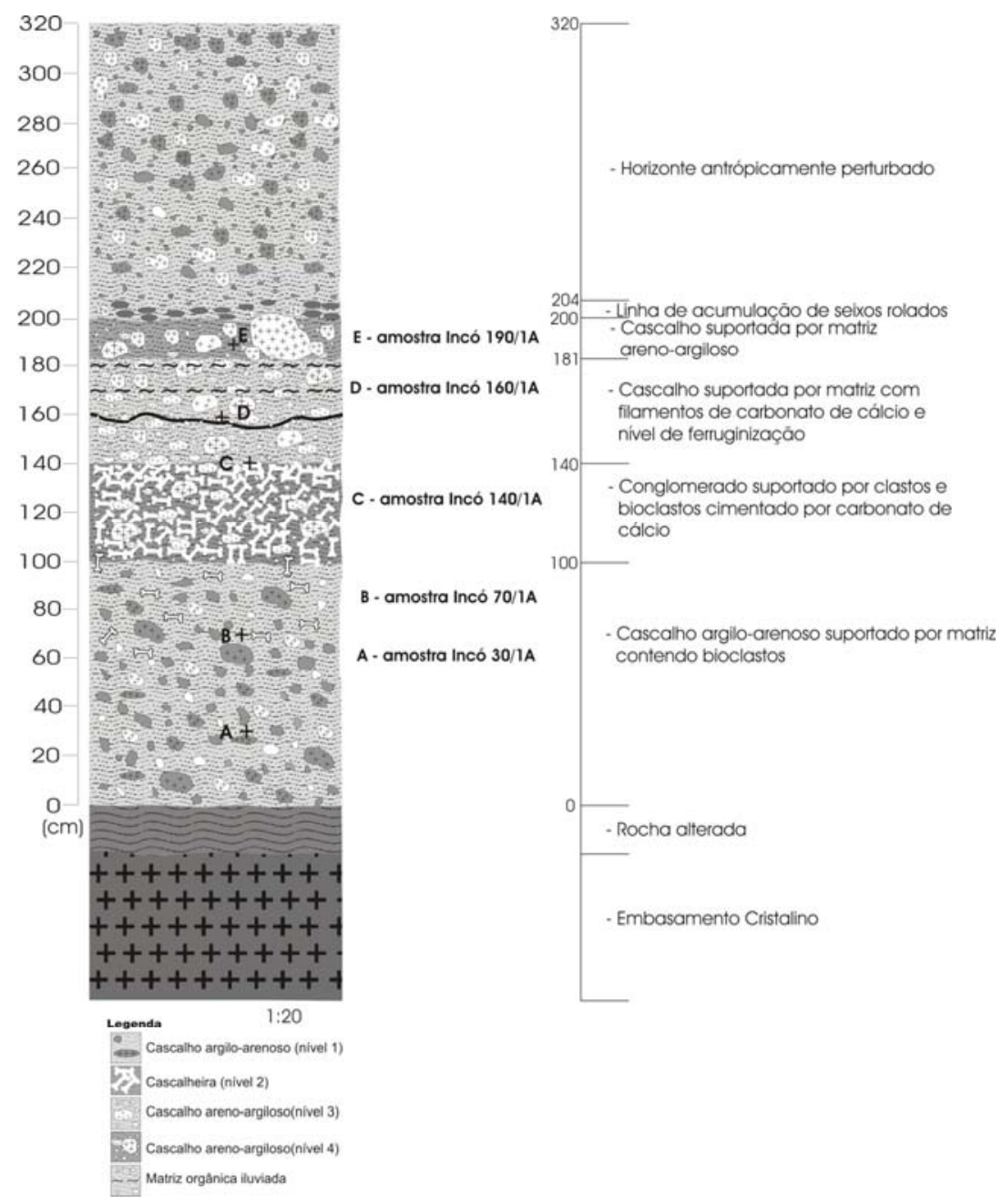

Figura 3: Seção vertical do depósito de tanque.

Silva, D. G.; Corrêa, A. C. B. 
O SIGNIFICADO DAS DATAS DE DEPOSIČÃO A PARTIR DA DATAÇÃO LUMINESCÊNCIA OPTICAMENTE ESTIMULADA (LOE)

$$
\text { Com base nas evidências }
$$

sedimentológicas apresentadas e na datação por LOE, foi possível reconstruir, qualitativamente, os diversos cenários da dinâmica geomorfológica responsável pelo preenchimento do tanque estudado. As concentrações de radioisótopos medidos e idades finais foram agrupadas na tabela 01 para uma melhor visualização dos resultados.

Tabela 01 - Distribuição anual de Th, U, K e cálculo das idades finais das amostras do tanque da Fazenda Logradouro, Fazenda Nova.

\begin{tabular}{l|ccccc|}
\multicolumn{1}{c}{ Parâmetros } & Incó 30/1A & Incó 70/1A & Incó 140/1A & Incó 160/1A & Incó 190/1A \\
\hline Th (ppm) & $5,294 \pm 0,191$ & $3,598 \pm 0,130$ & $3,333 \pm 0,120$ & $3,390 \pm 0,120$ & $4,503 \pm 0,162$ \\
U (PPM) & $2,816 \pm 0,199$ & $1,716 \pm 0,081$ & $2,095 \pm 0,108$ & $2,465 \pm 0,111$ & $2,121 \pm 0,180$ \\
K (\%) & $0,606 \pm 0,088$ & $0 \pm 0$ & $0 \pm 0$ & $0,256 \pm 0,037$ & $0,139 \pm 0,020$ \\
Dose Anual ( $\mathbf{H G y / a n o )}$ & $1.995 \pm 156$ & $1.167 \pm 60$ & $1.040 \pm 37$ & $1.403 \pm 76$ & $1.277 \pm 79$ \\
P (Gy) & 47,13 & - & 61,25 & 63,09 & 25,28 \\
Idade LOE BP (ano) & $23.600 \pm 3.100$ & - \pm- & $58.900 \pm 5.000$ & $45.000 \pm 4.700$ & $19.800 \pm 2.200$ \\
\cline { 2 - 6 }
\end{tabular}

Analisando em escala temporal a estratigrafia do depósito de tanque foi possível reconstruir qualitativamente os cenários de deposição responsáveis pelo seu preenchimento, percebendo-se que alguns eventos estão relacionados a ritmos climáticos já conhecidos para o Nordeste do Brasil desde o Pleistoceno Superior.

A unidade basal é marcada por uma remoção das coberturas residuais do entorno do tanque por fluxos de detritos de baixa viscosidade associados, provavelmente à atuação de sistemas meteorológicos convectivos em períodos de aridez concernentes ao anti-penúltimo estadial sob vegetação de caatinga arbóreo-arbustiva, que serviu como um anteparo para os clastos maiores liberando apenas as frações grossas.

Durante o penúltimo interestadial, a cerca de 58,9 Ka, a paisagem foi marcada por uma remobilização maciça dos fragmentos clásticos das coberturas superficiais. Este evento está

Silva, D. G.; Corrêa, A. C. B. 


\section{RBGF- Revista Brasileira de Geografia Física}

Recife-PE, Vol.2 n.02, maio-agosto 2009, 43-56

associado a uma cobertura vegetal aberta após período de secura prolongada deixando disponível sobre a superfície apenas os materiais mais grossos (ossos da megafauna e fragmentos de rochas) sendo removidos por movimentos de massa sob condições torrenciais, dando origem a uma cascalheira que posteriormente se converteria em conglomerado sob cimentação carbonática.

No penúltimo estadial do Pleistoceno, com temperaturas rebaixadas e predominância de períodos bastante secos em relação à fase anterior, eventos isolados de alta precipitação promoveram a remoção dos materiais rudáceos para o eixo do tanque. O evento datado em $45 \mathrm{Ka}$, reforça a interpretação de eventos ocasionais de alto grau pluviométrico inseridos em um clima mais frio e seco durante este período.

Existiu ainda um período mais seco relacionado ao UMG, o que corresponderia a uma pausa na sedimentação terrígena e formação de carbonato de cálcio. A ocorrência de longos períodos de extrema aridez seguidos de períodos com precipitação proporcionou oscilações mais ou menos rápidas ou pronunciadas do nível d’água favorecendo a carbonatação através da mobilidade do carbonato de cálcio no perfil.
O UMG na área foi marcado por uma nova remobilização dos mantos de intemperismo relacionada a um clima provavelmente mais frio e seco com eventos de chuvas sazonais de alta magnitude, a cerca de 19,8 Ka.

\section{CONCLUSÃO}

A partir da análise morfoestratigráfica associada à geocronologia dos materiais do depósito de tanque da Fazenda Logradouro é possível inferir alguns cenários paleoambientais. A distribuição estratigráfica das idades obtidas sugere uma dinâmica episódica de remoção dos mantos de alteração, com pulsos temporalmente bem marcados, atestando que a área estudada estocou sedimentos durante episódios de maior entrada de energia no sistema climático, e que esses repercutiram sobre o sistema erosivo/deposicional, deixando evidências na paisagem desde pelo menos o penúltimo máximo glacial.

Uma cronologia detalhada dos eventos geomórficos de Fazenda Nova não poderia ter sido realizada sem o uso da LOE, o que demonstra claramente que esta técnica de datação, combinada aos estudos geomorfológicos de detalhe, oferece uma oportunidade de melhor entendimento a cerca 


\section{RBGF- Revista Brasileira de Geografia Física}

Recife-PE, Vol.2 n.02, maio-agosto 2009, 43-56

da temporalidade das mudanças sofridas pela paisagem. Dessa forma foi possível aferir que os eventos de acumulação de sedimentos analisados foram pontuais, ou pelo menos os sedimentos que conseguem permanecer nas bacias de acumulação não indicam um processo de agradação lento e contínuo, mas a ocorrência de eventos deposicionais discretos e de curta duração. Entretanto, a principal dificuldade de qualquer proposta interpretativa para a área reside no fato de que os depósitos de tanques, da forma que se encontram na paisagem, representam apenas uma pequena parcela dos materiais originais que se moveram das porções superiores das encostas e divisores.

Outro dado importante refere-se aos mecanismos climáticos atuantes na geração dos depósitos, pois aparentemente esses não refletem apenas a ocorrência de momentos transicionais como de climas mais secos para climas mais úmidos, mas também refletem a ocorrência de eventos máximos mesmo durante a égide de climas provavelmente mais secos, como registrados pela ocorrência de calcrete no depósito de tanque de Fazenda Nova. Este padrão indica que a utilização dos depósitos de encosta como marcadores paleoclimáticos não revela uma composição binomial de tipos climáticos e respostas erosivo-deposicionais, mas sim um intricado

Silva, D. G.; Corrêa, A. C. B. padrão onde eventos de grande magnitude que se intercalam a eventos de recorrência mais frequentes, por vezes até superando estes últimos na sua capacidade de elaborar formas agradacionais que sobrevivam por muito tempo como estrutura superficial da paisagem. 


\section{RBGF- Revista Brasileira de Geografia Física}

Recife-PE, Vol.2 n.02, maio-agosto 2009, 43-56

\section{REFERÊNCIAS}

AITKEN, M. J. An Introduction to Optical Dating: the dating of Quaternary sediments by the use of photon-stimulated luminescence. Oxford: Oxford University Press, 1998. 267 p.

CAMARGO FILHO, M. \& BIGARELLA, J. J. Correlação de parâmetros estatísticos de sedimentos de vertentes, rampas de colúvioalúvio e terraço de várzea da bacia do Bananas - Guarapuava - PR. Geosul, v. 14, p. $438-442,1998$.

CORRÊA, A. C. B. et al. Evidência de Dessimetria Temporal da Dinâmica Geomorfológica Quaternária entre o Planalto da Borborema e Setores da Mantiqueira, Nordeste e Sudeste do Brasil, a partir da Datação de Sedimentos Alúvio-Coluvionares pelo Método da Luminescência Opticamente Estimulada (LOE). Portal do São Francisco, 3 (3): 21-45, 2004.

FRYE, J. C. \& WILLMAN, H. B. Morphostratigraphic units in Pleistocene stratigraphy. Am. Assoc. Petroleum Geologists Bull., v.46, p.112-113, 1962.

GEOFREY-SMITH, D. I. et al. Optical dating studies of quartz and feldspar sediment extracts. Quaternary Science Reviews, v.7, p.373-380, 1988.

HUNTLEY, D. J. et al. Optical dating of sediments. Nature, v. 313, p. 105-107, 1985.

HUNTLEY, D. J. et al. Thermoluminescence spectra of some mineral samples relevant to thermoluminescence dating. Journal of Luminescence, v. 39, p. 123 -136, 1988.

MEIS, M. R. M. \& MOURA, J. R. S. Upper Quaternary sedimentatiosn and hillslope

Silva, D. G.; Corrêa, A. C. B. evolution: Southeastern Brasilian Plateau. American Journal of Science, Vol. 284, March, p. 241-254, 1984.

MODENESI M.C. \& TOLEDO M.C.M. Weathering and formation of hillslope deposits in the tropical highlands of Itatiaia - southeastern Brazil. Catena,v.27,p.81-104, 1996.

MOURA, J. R. S. Geomorfologia do Quaternário. In: GUERRA, A. J. T.; CUNHA, S. B. (orgs). Geomorfologia: Uma Atualização de Bases e Conceitos. $5^{\circ}$ ed. Rio de Janeiro: Bertrand Brasil, 2003. p. 335-364.

MOURA, J. R. S. \& MEIS, M. R. M. Contribuição à estratigrafia do Quaternário Superior no médio vale do rio Paraíba do sul, Bananal (SP). Anais da Academia Brasileira de Ciências, Rio de Janeiro, v. 58, p. 89 - 102, 1986.

MOURA, J. R. S.; MELLO, C. L. Classificação aloestratigráfica do Quaternário superior da região de Bananal (SP/RJ). Revista Brasileira de Geociências. V. 21, p. 236 - 254, 1991.

STOKES, S. Luminescence dating applications in geomorphological research. Geomorphology, v. 29, p. 153 - 171, 1999.

SUGUIO, K. Geologia do Quaternário e mudanças ambientais (presente + passado $=$ futuro?). São Paulo: Paulo’s, 1999.

WAGNER, G. A. Age Determination of Young Rocks and Artifacts: physical and chemical clocks in Quaternary geology and archaeology. Springer, New York: Springer, 1998, 466p. 